\title{
SUPPLY CHAIN MANAGEMENT GULA MERAH KELAPA UD NIRWANA DI DESA DAYU KECAMATAN NGLEGOK KABUPATEN BLITAR
}

\section{Supply Chain Management of UD Nirwana Coconut Red Sugar In Dayu Village, Nglegok District, Blitar Regency}

\author{
A. Dwi Apriyanti Kumalasari ${ }^{*}$, Andik Suprayitno ${ }^{2}$, Rini Ratna Nafita \\ Sari $^{3}$, Imam Suhaimi ${ }^{4}$ \\ 1,2,4 Agribisnis Universitas Kahuripan Kediri, Kediri 64211, Indonesia. \\ ${ }^{3}$ Manajemen Universitas Kahuripan Kediri, Kediri 64211, Indonesia. \\ Email : dwiapriyantik@kahuripan.ac.id, andikray2@gmail.com, \\ riniratna@kahuripan.ac.id, suhaimi_yes@kahuripan.ac.id
}

\begin{abstract}
ABSTRAK
Penelitian supply chain management gula merah kelapa dilakukan pada UD Gula Nirwana Blitar Desa Dayu dengan tujuan mencari supply chain dan nilai harga di setiap titik pasar. Metode yang dipakai adalah analisis kuantitatif dan kualitatif yakni dengan cara observasi, survei, dokumentasi, dan wawancara. Sampel data diambil secara snowball sampling method yakni sejumlah pedagang pasar yang ada di kawasan Kabupaten Blitar sampai ke pengguna akhir. Pengepul membeli gula merah kelapa dari UD Gula Nirwana harga Rp 14.000/kg dan dijual kepada sejumlah agen dengan harga $\mathrm{Rp} 14.500 / \mathrm{kg}$. Agen menjual gula merah kelapa kepada pengecer dengan harga $\mathrm{Rp} 15.000 / \mathrm{kg}$. Di tingkat pengecer harga gula merah kelapa berkisar Rp 15.500-15.700/kg. Panjangnya supply chain yang terjadi karena tidak semua konsumen gula merah kelapa di berbagai daerah mendapatkan gula merah dari UD Gula Nirwana secara langsung seperti yang dilakukan pabrik kecap Tjapar dan Roti Orion Blitar, melainkan dari pengepul yang membeli gula merah di UD Gula Nirwana kemudian kepada agen, agen ke pengecer, selanjutnya pengecer kepada konsumen akhir. Perlunya memotong supply chain dengan cara pengrajin langsung mendistribusikan kepada pengecer agar pengrajin mendapatkan peningkatan margin dan pengguna akhir bisa mendapatkan harga lebih murah.
\end{abstract}

Kata Kunci: Gula Merah, Supply Chain, Kelapa

\begin{abstract}
Research on the supply chain management of coconut palm sugar was carried out by UD Gula Nirwana Blitar in Dayu Village with the aim of finding the supply chain and price value at every market point. The method used is quantitative and qualitative analysis, namely by means of observation, surveys, documentation, and interviews. Data samples
\end{abstract}


were taken using the snowball sampling method, namely a number of market traders in the Blitar Regency area to the end users. Collectors buy coconut brown sugar from UD Gula Nirwana at a price of Rp. 14,000/kg and sell it to a number of agents at a price of IDR $14,500 / \mathrm{kg}$. The agent sells coconut brown sugar to retailers at a price of IDR 15,000/kg. At the retail level, the price of coconut brown sugar ranges from IDR 15,500-15,700/kg. The length of the supply chain occurs because not all consumers of coconut brown sugar in various regions get brown sugar directly from UD Gula Nirwana, as did the soy sauce factory Tjapar and Roti Orion Blitar, but from collectors who buy brown sugar at UD Gula Nirwana and then to the agent, agents to retailers, then retailers to final consumers. The need to cut the supply chain by direct distribution to the retailers so that the craftsmen get an increase in margins and end users can get lower prices.

Keywords: Brown Sugar, Supply Chain, Coconut

\section{PENDAHULUAN}

Salah satu sektor yang memiliki peran penting dalam pembangunan perekonomian di Indonesia adalah sektor pertanian (Suliantoro, Hery; Nugrahani, 2015). Gula merupakan salah satu kebutuhan pokok dari sembilan kebutuhan pokok rakyat Indonesia. Gula merupakan komoditas strategis dalam mencukupi kebutuhan pangan masyarakat luas. Hal ini ditunjang dengan pendapat dari Wiranata (2013) bahwa gula merupakan komoditas pangan strategis setelah beras. Gula merah sendiri merupakan bahan yang sering digunakan sebagai campuran pembuatan produk-produk bumbu dan makanan (Rahmah, 2016). Gula merah memiliki nutrisi yang baik bagi tubuh dengan kandungan mineral yang cukup tinggi, hal ini sesuai dengan pendapat Rahmah (2016) bahwa gula merah memiliki kandungan kalsium, fosfor dan zat besi yang lebih tinggi dibandingkan gula pasir. Gula merah kelapa salah satu bagian dari gula merah yang difungsikan sebagai bahan tambahan pangan untuk keperluan industri dan keperluan masak di tingkat rumah tangga.

Mekanisme pembentukan harga akhir kepada konsumen tidak lepas dari kegiatan yang dilakukan untuk membawa barang dari tempat produksinya ke lokasi-lokasi penjualan untuk menjangkau konsumen (Sutandi, 2018). Gula merah kelapa mampu menciptakan berbagai harga di pasar dikarenakan setiap pelaku pemasaran ingin mendapatkan keuntungan dari produk yang diperdagangkan. Hal ini sejalan dengan pendapat Pranatagama (2015) bahwa perbedaan harga di masing-masing lembaga pemasaran sangat bervariasi tergantung dari besar kecilnya keuntungan yang diambil oleh masing-masing lembaga perantara pemasaran. Perbedaan harga tersebut dimulai dari pengrajin, pengepul, pengecer, sampai pengguna terakhir (konsumen akhir). Supply chain yang terlalu panjang bisa mengakibatkan harga gula merah terlalu tinggi untuk diterima oleh konsumen akhir. 
Blitar merupakan Kabupaten yang berada di Jawa Timur dan terkenal dengan pengrajin gula merah kelapa. Usaha Dagang (UD) Gula Nirwana merupakan salah satu pengepul terbesar yang ada di Kecamatan Nglegok, tepatnya berada di Desa Dayu. Sejalan dengan hal tersebut para petani harus tetap mendapatkan penghasilan dengan menjaga keberadaan gula merah dalam pasaran. Pembangunan SDM kepada petani sangat berperan penting agar petani mampu meningkatkan produksi dan produktifitas. Hal ini juga akan berkaitan dengan peningkatan kualitas produk seperti daya saing produk, harga produk, biaya transportasi, biaya penyimpanan hingga ketepatan dalam pengiriman barang. Keunggulan daya saing produk ini jika dijaga dengan baik, maka kontinuitas produk akan terjaga (Kumalasari, 2020).

Manajemen rantai pasokan adalah suatu konsep atau mekanisme untuk meningkatkan produktivitas total perusahaan dalam rantai pasokan melalui optimalisasi waktu, lokasi dan aliran kuantitas bahan (Pongoh, 2016). Pentingnya peranan pengrajin gula dan manajemen rantai pasokan, maka perlu dilakukan peninjauan mengenai supply chain management gula merah kelapa yang dilakukan oleh salah satu pengepul yang ada di Desa Dayu Kecamatan Nglegok, Kabupaten Blitar. Tujuan dari sebuah Supply Chain Management (SCM) adalah untuk memenuhi permintaan pelanggan melalui penggunaan sumber daya yang paling efisien, termasuk kapasitas distribusi, persediaan, dan sumber daya manusia (Nurhasanah \& Aspiranti, 2020). Menurut Anwar (2011) penerapan manajemen rantai pasok di masa sekarang cocok untuk diterapkan karena memiliki kelebihan dimana mampu mengelola aliran barang dalam suatu rantai pasok. UD Gula Nirwana menjadi salah satu tempat dimulainya penelitian ini guna menelusuri proses alur barang sampai kepada konsumen akhir untuk dapat mengidentifikasi supply chain yang terjadi di dalamnya, terutama kordinasi dan sumber informasi lainnya yang terlibat.

Manajemen rantai pasok yang baik akan berdampak pada setiap industri gula untuk menghasilkan produk yang tepat waktu dan tempat (Mayangsari, 2020). Supply chain management sangat penting untuk mempercepat proses produksi dan proses pemasaran untuk memenuhi kebutuhan konsumen khususnya agen dari UD Gula Nirwana. Hal ini dikarenakan UD Gula Nirwana merupakan pemasok terbesar di Blitar. Manajemen rantai pasok gula merah kelapa di UD Gula Nirwana yang berada di Desa Dayu Kecamatan Nglegok dilakukan oleh beberapa pelaku rantai pasok. Beberapa pelaku rantai pasok yang melakukan transaksi jual beli gula merah kelapa di daerah tersebut sangat membantu proses pemasaran produk gula merah kelapa di daerah tersebut. Namun semakin panjang rantai pasok yang terjadi dapat memengaruhi harga jual yang diterima pengrajin dibandingkan harga jual dipasaran menjadi berbeda jauh atau memiliki selisih harga jual yang tinggi. Selain itu dampak pembatasan mobilitas melalui PSBB dan protokol kesehatan lainnya, mendorong aktivitas masyarakat untuk pemenuhan kebutuhan pangan pokok menjadi terbatas. 
Penerapan PSBB menjadi kendala bagi kegiatan rantai pasok komoditas pangan pokok dan strategis sehingga harga eceran umumnya meningkat (Anugrah et al., 2020). Di Kecamatan Nglegok terdapat beberapa pengepul yang berusaha membantu proses pemasaran produk gula di daerah tersebut. Peneliti mengambil sampel penelitan di UD Gula Nirwana yang berada di Desa Dayu Kecamatan Nglegok Kabupaten Blitar sebagai salah satu pengrajin sekaligus pengepul yang berpengaruh terhadap manajemen rantai pasok gula merah kelapa di Desa Dayu. Sehingga dari hal tersebut bisa didapatkan perumusan masalah, yakni bagaimana penerapan manajemen rantai pasok gula merah kelapa di Desa Dayu Kecamatan Nglegok, Kabupaten Blitar?

\section{METODOLOGI}

\section{Lokasi dan Waktu Penelitian}

Lokasi penelitian di UD Gula Nirwana sebagai pengrajin sekaligus pengepul gula merah kelapa di Desa Dayu, Kecamatan Nglegok Kabupaten Blitar, Jawa Timur hingga ke tempat konsumen akhir gula merah kelapa dengan waktu penelitian Maret hingga Agustus 2021. Pemilihan lokasi dilakukan dengan metode purposive dikarenakan UD Gula Nirwana merupakan produsen gula merah kelapa terbesar di Blitar sehingga dianggap lebih representatif.

\section{Metode Analisis}

Metode yang dipakai analisis kuantitatif dan kualitatif yakni dengan cara observasi, survei, dokumentasi, dan wawancara. Sampel data diambil secara snowball sampling method yakni sejumlah pedagang pasar yang ada di kawasan Kabupaten Blitar sampai ke pengguna akhir serta data nilai harga setiap titik supply chain.

\section{HASIL DAN PEMBAHASAN}

\section{Penerapan Supply chain Manajemen pada UD Gula Nirwana}

Adapun mata rantai pembuatan gula merah kelapa UD Gula Nirwana dengan tiga tahapan. Tahapan pertama, pengolahan bahan baku nira kelapa yang sudah di panen setiap pagi dan sore. Tahapan kedua, proses pensortiran untuk mendapatkan kualitas produk yang baik, sedang, dan jelek. Tahapan ketiga yakni tahap pengemasan, biasanya dalam satu kantong plastik untuk ukuran cetakan batok kelapa besar memiliki berat $25 \mathrm{~kg}$ atau tergantung permintaan konsumen. Penyaluran gula merah kelapa kepada konsumen akhir diperlukan pihak-pihak yang terlibat dalam proses rantai pasok, diantaranya distributor baik pengepul dari suatu daerah, agen dan pengecer. Menurut Pongoh (2016) dalam rantai pasokan ada beberapa pemain utama yang mempunyai kepentingan di dalam arus barang, yaitu : 1) pemasok (supplier), 2) pabrik (manufacture), 3) distributor (wholesaler), 4) penyalur (retail outlets) dan 5) konsumen (customers). Pernyataan tersebut sesuai dengan pendapat Wuwung (2013) bahwa manajemen rantai 
pasokan adalah sebuah sistem yang melibatkan proses produksi, pengiriman, penyimpanan, distribusi dan penjualan produk dalam rangka memenuhi permintaan akan produk tersebut rantai pasokan didalamnya termasuk seluruh proses dan kegiatan yang terlibat didalam penyampaian produk tersebut sampai ke tangan pemakai konsumen. Berdasarkan hasil penelitian ini pelaku supply chain yang terlibat yakni meliputi :

1. Pemasok dalam hal ini adalah petani Nira.

2. Pabrik (Manufacture) yaitu UD Gula Nirwana yang mentrasformasikan bahan mentah menjadi barang dalam proses dan barang jadi.

3. Distributor yakni pengepul yang menjual produk gula merah kelapa kepada sejumlah penyalur atau pengecer. Dari distributor selanjutnya gula akan dijual ke sejumlah agen . Dalam Hal ini UD Gula Nirwana memiliki 2 distributor yaitu Pak Rudi dan Pak Qholil.

4. Agen yakni sejumlah toko-toko besar yang menjadi tempat kulakan pengecer.

5. Pengecer yakni melakukan penjualan secara langsung kepada konsumen akhir yang umumnya dalam skala kecil. Dalam proses penyaluran gula diperlukan juga informasi harga yang terjadi hal ini sesui dengan pendapat Kambey et al., (2016) bahwa supply chain menyangkut hubungan yang terus menerus mengenai barang, uang, dan informasi.. Berikut adalah gambaran supply chain management UD Gula Nirwana.

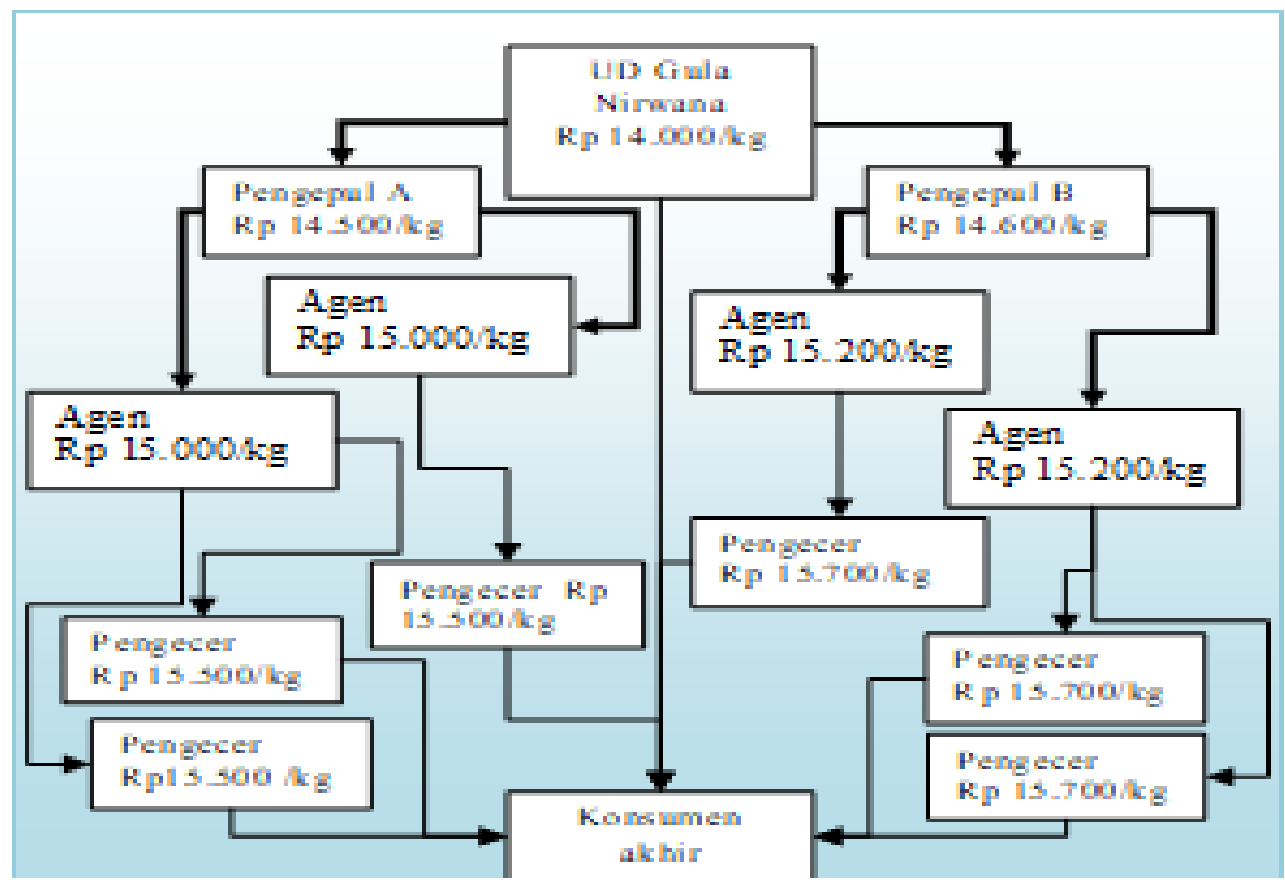

Gambar 1. Supply Chain Gula Merah Kelapa Yang Terjadi di UD Gula Nirwana Sumber: Data Primer, 2020 (diolah) 


\section{Keterangan :}

- Distributor atau Pengepul A : Bapak Rudi yang tinggal di Desa Dayu, menjual gula merah kelapa kepada sejumlah agen yang ada di pasar Kesamben.

- Distributor atau Pengepul B : Bapak Qholil yang tinggal di Kecamatan Pare, menjual gula merah kelapa kepada sejumlah agen yang ada di pasar Karangdinoyo, pasar Njowah, pasar Kandangan, pasar Papar, pasar Bogo, dan pasar Mbangsongan.

Harga yang diterima konsumen akhir dari setiap pelaku supply chain tergantung dari konsumen akhir yang membeli gula merah dari penjual. Konsumen akhir yang membeli gula merah kelapa di UD Gula Nirwana secara langsung menerima barang dengan harga Rp 14.000/kg, pihak konsumen akhir tersebut seperti pabrik kecap Tjapar dan rumah produksi Roti Orion Blitar. Sedangkan konsumen akhir yang membeli barang dari pengecer menerima

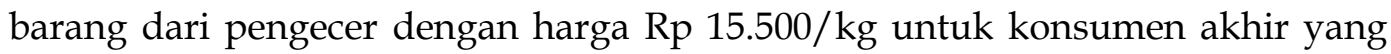
membeli gula di wilayah sekitar Blitar sedangkan konsumen akhir yang membeli gula di wilayah Kecamatan Pare dan sekitarnya menerima barang dari pengecer dengan harga Rp 15.700/kg.

Hasil temuan ini didukung oleh penelitian yang dilakukan oleh Supriyati (2011) yakni bahwa kegiatan operasional distribusi bisa sangat kompleks terutama bila pengiriman harus dilakukan ke jaringan yang luas dan tersebar dimana-mana. Perusahaan harus menetapkan tingkat servis level yang harus dicapai di masingmasing wilayah. Dalam supply chain gula merah kelapa yang dilakukan oleh UD Gula Nirwana harga yang diterima oleh pedagang pasar, baik pedagang di wilayah Kabupaten Blitar dan Kabupaten kediri relatif seimbang, yaitu untuk wilayah kabupaten Blitar Rp 15.500/kg dari pengecer ke konsumen akhir, dan untuk wilayah Kediri Rp 15.700/kg dari pengecer ke konsumen akhir. Hal tersebut dikarenakan proses supply chain yang terjadi sama yaitu, dari UD Gula Nirwana ke pengepul, dari pengepul ke sejumlah agen, dari agen ke pengecer, dan selanjutnya ke konsumen akhir. Selisih harga terjadi karena perbedaan jarak dari suatu daerah dan berpengaruh pada biaya transportasi yang harus dikeluarkan oleh masing-masing pelaku rantai pasok.

\section{KESIMPULAN DAN REKOMENDASI KEBIJAKAN}

\section{Kesimpulan}

Penerapan supply chain management gula merah kelapa di Desa Dayu Kecamatan Nglegok, Kabupaten Blitar sudah sesuai dengan kajian teori yang disampaikan oleh Pongoh (2016), yakni terdiri dari Supplier-Distributor atau Pengepul-Agen-Pengecer-Konsumen Akhir. Distributor terdiri atas 2 orang yakni wilayah Blitar dan Kediri. Sehingga menyebabkan panjangnya rantai pasokan yang terjadi, yang pada akhirnya menyebabkan harga jual yang cukup tinggi ketika sampai pada konsumen akhir. 


\section{Rekomendasi Kebijakan}

Perlunya memotong mata rantai supply chain yakni dengan menambah jumlah distributor di berbagai wilayah dengan jumlah permitaan tertinggi berdasarkan riwayat data penjualan. Hal ini dimaksudkan pengrajin mendapatkan peningkatan margin dan pengguna akhir bisa mendapatkan harga lebih murah.

\section{DAFTAR PUSTAKA}

Anugrah, I. S., Saputra, Y. H., \& Sayaka, B. (2020). Dampak Pandemi Covid-19 Pada Dinamika Rantai Pasok Pangan Pokok. Pse.Litbang.Pertanian.Go.Id, 3, 297-319. http://pse.litbang.pertanian.go.id/ind/pdffiles/15-BBRC2020-III-2-3-ISA.pdf

Anwar, S. N. (2011). Manajemen Rantai Pasokan (Supply chain Manajemen). Majalah Ilmiah Gema Maritim, 13(1), 20-28. https:// doi.org/10.37612/gema-maritim.v13i1.19

Kambey, S. F., Kawet, L., \& Sumarauw, J. S. B. (2016). Analisis Rantai Pasokan (Supply chain) Kubis Di Kelurahan Rurukan Kota Tomohon(Analysis Supply chain Cabbage In Kelurahan Rurukan Tomohon City). Jurnal EMBA, 4(5), 303-406.

Kumalasari, D. A. (2020). Pembangunan Pertanian Berbasis Agribisnis di Era dan $\begin{array}{llll}\text { Pasca } & \text { Covid } 19 . & \text { Agriovet, } 28 \text {, }\end{array}$ https:// ejournal.kahuripan.ac.id/index.php/agriovet/article/view/359

Mayangsari, A. (2020). Identifikasi Kondisi Rantai Pasok Tebu Di Pabrik Gula Wringin Anom Kabu- paten Situbondo Identification of the Condition the Sugarcane Supply chain at the Wringin Anom Sugar Factory, Situbondo Regency. 2020, 108-113.

Nurhasanah, S., \& Aspiranti, T. (2020). Analisis Pengukuran Kinerja Supply chain Manajemen Pada Komoditi Ubi Jalar dengan Menggunakan Metode SCOR Di PT . Bimandiri Agro Sedaya. 6, 728-733.

Pongoh, M. (2016). Analisis Penerapan Manajemen Rantai Pasokan Pabrik Gula Aren Masarang. Jurnal Riset Ekonomi, Manajemen, Bisnis Dan Akuntansi, 4(3),695-704.

https:/ / ejournal.unsrat.ac.id/index.php/emba/article/view/14368

Pranatagama, M. F. (2015). Efisiensi dan Bauran Pemasaran Usaha Tani Kacang Tanah di Desa Darungan Kecamatan Tanggul Kabupaten Jember. 1-49.

Rahmah, F. A. (2016). Pengaruh Penggunan Jenis Gula Merah dan Lama Fermentasi terhadap Karakteristik Water Kefir. Skripsi Program Studi Teknologi Pangan Universitas Pasundan, 1-57. 
Suliantoro, Hery; Nugrahani, D. (2015). Pengukuran Dan Evaluasi Kinerja Supply Chain Dengan Menggunakan Pendekatan Balanced Scorecard-Analytical Network Process (Bsc-Anp) Di Pt. Madubaru Yogyakarta. 6, 17-23.

Supriyati. (2011). Kaji Ulang Konsep Neraca Gula Nasional: Konsep Badan Ketahanan Pangan vs Dewan Gula Indonesia National Sugar Balance Sheets Reassessment: Concepts of Food Security Agency vs Indonesian Sugar Council Gula merupakan salah satu komoditas pangan strategis. Analisis Kebijakan Pertanian, 9(2), 109-124.

Sutandi, S. (2018). Model Jaringan Rantai Pasok Pasar Tradisional Untuk Komoditas Gula Kristal Putih Di Provinsi Jawa Barat. Jurnal Logistik Indonesia, 1(1), 7-16. https:// doi.org/10.31334/jli.v1i1.124

Wiranata, Y. S. (2013). EDAJ 2 (1) (2013) Faktor-Faktor Yang Mempengaruhi Impor Gula Pasir Di Indonesia Tahun 1980-2010 Yayan Sukma Wiranata. Economics Development Analysis Journal, 2(1), 1-2. http://journal.unnes.ac.id/sju/index.php/edaj

Wuwung, S. C. (2013). Manajemen Rantai Pasokan Produk Cengkeh Pada Desa Wawona Minahasa Selatan. Jurnal Riset Ekonomi, Manajemen, Bisnis Dan Akuntansi, 1(3), 230-238. https:// doi.org/10.35794/emba.v1i3.1731 